\title{
LAS NORMAS DE COMPORTAMIENTO ÉTICO EN EL MANEJO DE LA INFORMACIÓN PRIVILEGIADA EN LA LEY REGULADORA DEL MERCADO DE VALORES
}

\author{
FEDERICO MONTIEL CASTILLO \\ Sistema de Estudios de Posgrado \\ Universidad Estatal a Distancia \\ fmontiel@uned.ac.cr
}

\section{RESUMEN}

Las normas de conducta en el manejo de la información privilegiada en la Ley Reguladora del Mercado de Valores son postulados importantes que fortalecen los principios de confianza, protección al inversor y la seguridad que debe prevalecer en el sistema del mercado de valores. Estas normas de conducta son principios éticos que rigen el actuar no solo de los funcionarios públicos que puedan tener acceso a la misma, sino también a una serie de colaboradores que en ocasión de sus funciones puedan conocerla y procurar un beneficio indebido para sí, para un tercero o bien para un grupo de interés económico, lo que a la postre puede significar un impacto negativo no solo en el sistema de valores sino también en la confianza del público inversor como actor fundamental.

PALABRAS CLAVES: INFORMACIÓN PRIVILEGIADA, PUESTO DE BOLSA, DELITOS BURSÁTILES, RESPONSABILIDAD DEL FUNCIONARIO, JUNTA DIRECTIVA, SUGEVAL.

\section{ABSTRACT}

Conduct regulations related to the management of privileged information as stated in the Securities Market Regulating Law are important principles that strengthen the trust, protection, and safety of investors that should prevail in the market system. These rules of conduct are ethical principles that govern the actions, not only of public officials who may have access to specific information, but also to a number of collaborators that, thanks to their functions, can know it, too, and who may procure an undue advantage for themselves, for a third party or for a group of economic interest, a situation that, ultimately, may bring a negative impact, not only on the value system, but also on the confidence of a key player: the investing public.

KEYWORDS: INSIDE INFORMATION, POST BAG, STOCK MARKET CRIMES, RESPONSIBILITY OFFICER, BOARD, SUGEVAL.

\section{Introducción}

El Mercado de Valores es una amalgama de relaciones jurídicas por medio de las cuales se da sustrato a una actividad económica de especial importancia para cualquier mercado económico. Esta materia, dada su especificidad, la encontramos en la Ley Reguladora del Mercado de Valores, por directrices de la Superintendencia General de Valores. A través de esta normativa se brindan pautas específicas sobre los deberes y obligaciones de los agentes económicos, así como las personas que participan directa o indirectamente del mercado de valores. Estos postulados obligan a una serie de comportamientos éticos sobre el manejo de la información privilegiada o bien "de primera mano", que puedan tener a su alcance agentes o participantes de este sector específico, y que podría generarles por su divulgación, una situación privilegiada sobre las acciones a seguir frente a los comportamientos que puedan acaecer en el mercado financiero. Estas disposiciones cubren tanto a personeros de la SUGEVAL, Puestos de Bolsa, Agentes y otras entidades que integran el mercado de valores. 


\section{Metodología}

En este artículo se usará la metodología descriptiva para analizar las normas de comportamiento ético y de responsabilidad que contiene la Ley Reguladora del Mercado de Valores en Costa Rica en el uso de la información privilegiada.

En los dos primeros apartados se abordará la creación y la importancia del Banco Central de Costa Rica como piedra angular del sistema financiero. Posteriormente, se abordará la creación de la Superintendencia General de Valores (SUGEVAL), la Bolsa Nacional de Valores y los Puestos de Bolsa.

En el último acápite se hará referencia a las normas que contienen los postulados éticos relacionados con el manejo de la información privilegiada o clasificada, así como el régimen sancionatorio que contiene la Ley Reguladora del Mercado de Valores.

\section{El Banco Central de Costa Rica}

El Banco Central de Costa Rica (BCCR) es una institución fundamental para la organización del sistema bancario y financiero costarricense.

Derivado de la nacionalización bancaria, mediante la Ley número 1130 del 28 de enero de 1950, el Banco de Central de Costa Rica asume un papel preponderante en la vida económica de Costa Rica.

Según Arias (1998), la Junta de Gobierno en realidad no buscó nacionalizar la banca en general, sino la facultad de recibir depósitos del público, lo que pasó a manos del Estado y con ello, logró el control de la actividad más importante de la banca: la facultad de prestarle al público disponiendo del ahorro nacional.

Para darle las funciones necesarias se dictó la Ley número 1552, denominada Ley Orgánica del Banco Central, la cual fue posteriormente modificada por la Ley número 7558 del 3 de noviembre de 1995.
Dentro de las funciones del Banco Central de Costa Rica se enuncian las siguientes: a) El mantenimiento del valor externo y de la conversión de la moneda nacional, b) La custodia y la administración de las Reservas Monetarias internacionales de la Nación, c) La definición y el manejo de la política cambiaria y monetaria, d) La gestión como Consejo y banco-cajero del Estado; e) La promoción de condiciones favorables al robustecimiento, la liquidez, la solvencia y el buen funcionamiento del Sistema Financiero Nacional.

Para efectos de este Artículo, resulta de vital importancia circunscribir las relaciones que se derivan de la promulgación de la Ley Reguladora del Mercado de Valores.

\section{La Superintendencia General de Valores (SUGEVAL)}

Con la promulgación de la Ley 7732 el 27 de marzo de 1998 se crea la Superintendencia General de Valores, la cual es un órgano de desconcentración máxima adscrito al Banco Central de Costa Rica. Previo a su creación, la regulación del mercado de valores recaía sobre la Comisión Nacional de Valores (CNV), la cual se regulaba en su actuar por la primera Ley Reguladora del Mercado de Valores n. ${ }^{\circ} 7201$.

La Ley Reguladora del Mercado de Valores vigente vino a robustecer y brindar un mayor respaldo al mercado financiero.

Para Rojas (1997) tradicionalmente el sistema financiero se divide en dos grandes mercados: el mercado de dinero o monetarios y el mercado de capitales. El primero abarca la actividad crediticia que se realiza a través de operaciones a corto plazo, o sea, aquellas que se generan de la interacción de oferentes y demandantes de fondos de corto plazo. Por su parte, el mercado de capitales comprende las actividades que permiten la financiación a mediano y largo plazo, como por ejemplo, las transacciones de bonos. 
De igual manera, se crea la Superintendencia General de Valores conocida por sus siglas (SUGEVAL): "Artículo 3.- Creación y funciones: "Créase la Superintendencia General de Valores, denominada en esta ley la Superintendencia, como órgano de máxima desconcentración del Banco Central de Costa Rica."

La SUGEVAL, dada su naturaleza jurídica de órgano de desconcentración máxima, guarda con la Junta Directiva del Banco Central de Costa Rica una relación de dirección, ya que sigue perteneciendo a la estructura organizativa de dicha entidad, donde no existe una relación de jerarquía propiamente dicha, sino una labor directiva.
Según Soto (2003), la Superintendencia General de Valores es una entidad públia altamente especializada, cuyo principal objetivo es proteger a los inversionistas que operan en el mercado costarricense de valores. Para ello debe velar por la transparencia del mercado de valores, la formación correcta de los precios y la difusión de la información necesaria para alcanzar los objetivos.

En la Figura 1 se describe la organización actual que muestra la SUGEVAL, así como las diferentes dependencias administrativas que la integran.

FIGURA 1

\section{ORGANIZACIÓN DE LA SUPERINTENDENCIA GENERAL DE VALORES}

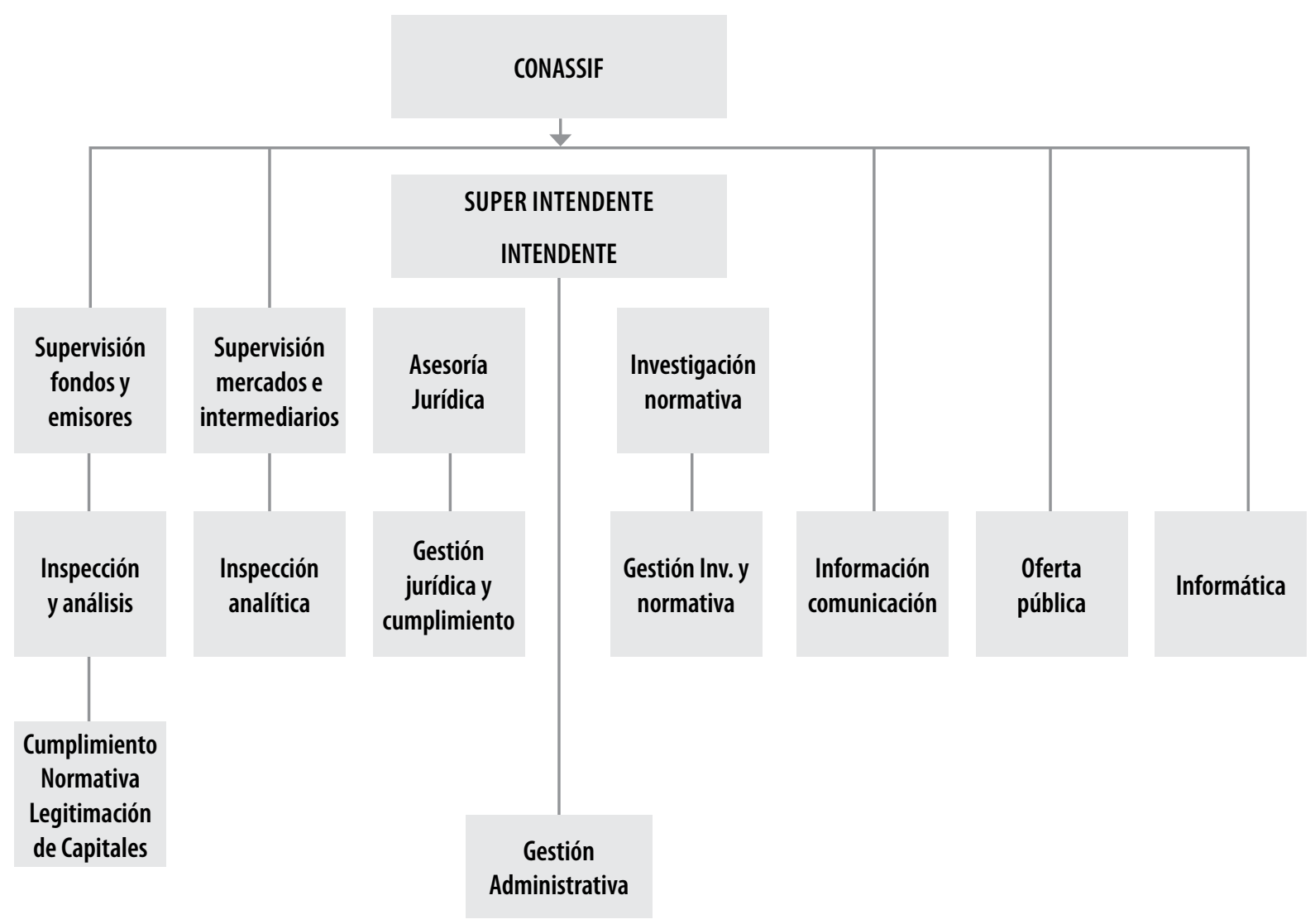

Fuente: www.sugeval.fi.cr 
Le corresponde a SUGEVAL, como importantes funciones, regular, supervisar y fiscalizar los mercados de valores, así como la actividad de los agentes que participan en él.

Las funciones de la SUGEVAL en el tema de acceso a la información son:

"Artículo 5.- Funciones anexas (Además de las que le confieran otros artículos de esta ley, la Superintendencia tendrá las siguientes funciones: a tales empresas: g) Exigir, a los sujetos fiscalizados, toda la información razonablemente necesaria, en las condiciones y periodicidad que la Superintendencia determine, para cumplir adecuadamente con sus funciones supervisoras del mercado de valores, según lo disponga el reglamento. Para ello, podrá ordenar sin previo aviso visitas de auditoría a los sujetos fiscalizados. La Superintendencia podrá realizar visitas de auditoría a los emisores solo excepcionalmente, con el fin de aclarar la información de las auditorías".

De lo que establece la norma, es clara la potestad supervisora según lo considere pertinente la SUGEVAL, en relación con los sujetos fiscalizados. Dichas potestades son una derivación que el Estado ha delegado en esta entidad pública para que sea un garante del correcto funcionamiento del mercado.

Según Camacho (2001), los prerrequisitos de supervisión eficaz están relacionados con la vigente de un marco institucional y regulatorio adecuado que facilite la estabilidad y la consistencia macroeconómica, que defina claramente las facultades y responsabilidades de los entes reguladores y supervisores, así que favorezca la aplicación eficaz de criterios de supervisión prudencial.

Como otro pilar rector de la estructuración del mercado financiero, encontramos que la transparencia y la actuación de buena fe en los negocios son fundamentales para un adecuado comportamiento no solo ético, sino también en las labores propias que le dan vida a tan importante valor económico. Es por esta razón, que los sujetos fiscalizados por la SUGEVAL tiene la obligación de entregar la información en la forma y dentro de las competencias que le otorga la ley a la SUGEVAL para que ella pueda cumplir con sus atribuciones de Ley y salvaguardar el comportamiento ético correcto en el mercado de valores.

Esta ley establece el Consejo Nacional de Supervisión del Sistema Financiero (CONASSIF), siendo este ente el que nombrará al Superintendente de Valores por un periodo de cinco años, como autoridad máxima de la Superintendencia y con la representación legal necesaria en su actuación administrativa.

\section{Estructuración del Mercado de Valores: El Mercado Primario y Secundario}

Corresponde ahora abordar la Regulación del Mercado de Valores en Costa Rica. Para lo anterior, el legislador creó la Ley Reguladora del Mercado de Valores, la cual brinda claras pautas sobre la participación de los distintos agentes económicos en el mercado de valores, la constitución de nuevos entes reguladores de la actividad, así como los tipos penales especiales.

La estructuración del mercado de valores es de reciente data en nuestro ordenamiento jurídico, ya que:

El mercado organizado de valores en nuestro país es relativamente joven. Se establece bajo la figura de la Bolsa Nacional de Valores, como parte de un esfuerzo estatal, que luego fue trasladado en su totalidad a manos privadas. Durante estos primeros años, que han sido básicamente parte de un proceso de nacimiento y aprendizaje por parte del mercado en general, ha habido elementos 
que han tenido una fuerte incidencia sobre el desempeño y orientación del mercado de bolsa. Se puede citar, a manera de ejemplo, las crisis económicas de la década de los ochenta, así como la crisis de liquidez de finales de la misma década, que causaron una fuerte conmoción a todo el sistema financiero nacional (Méndez, s.f.).

Según lo menciona Rodríguez (1995), en Costa Rica como en la mayoría de los países, los mercados de valores pertenecen al Sistema Financiero Nacional, el cual se define como el conjunto de instituciones, instrumentos y canales, encargados de promover administrar y dirigir el ahorro hacia la inversión, por medio de un gran mercado que permite el traslado de los recursos monetarios desde las unidades económicas que disponen de excedentes de esos recursos, o sea los ahorrantes, hasta aquellos que los necesitan, o sea los inversionistas.

La Ley Reguladora dispone: "Artículo 1.-Esta ley tiene por objeto regular los mercados de valores, las personas físicas o jurídicas que intervengan directa o indirectamente en ellos, los actos o contratos relacionados con tales mercados y los valores negociados en ellos".

Sobre la organización de los mercados, se ha dicho que se constituyen de la siguiente forma:

a) Mercado Primario: estará constituido por los títulos de primera mano, es decir, la venta directa de títulos valores por parte de los emisores y la compra de los mismos que realizan los puestos de bolsa en representación de ellos mismos y de sus inversionistas..."; b) Mercado Secundario: estará constituido por la compra venta de los títulos que han sido emitidos con anterioridad; es decir, no provienen del emisor y son vendidos en el mercado antes de su maduración con el fin de suministrar liquidez a sus poseedores (Matarrita, s.f.).
Según Arias (1998), mediante las operaciones de bolsa, las empresas obtienen dinero que se comprometen a devolver a mediano y largo plazo, generalmente por montos importantes, evitándose así el problema de los topes de crédito bancario, de sus plazos máximos y las altas tasas de interés. El Estado también utiliza este mercado de capitales, para colocar títulos públicos, mediante los que capta recursos para su financiamiento.

Dentro del amplio espectro de actividades que se desarrollan en el mercado de valores, la Ley Reguladora señala específicamente: "Artículo 10.- Objeto de oferta pública.-Solo podrán ser objeto de oferta pública en el mercado primario, las emisiones de valores en serie conforme a las normas dictadas reglamentariamente por la Superintendencia y autorizadas por ella".

Este importante postulado de la Ley Reguladora del Mercado de Valores circunscribe la actuación de la oferta pública de valores en un mercado primario bajo los preceptos que dictará Reglamentariamente la SUGEVAL. Esto tiene su razón de ser, ya que el desarrollo de las actividades financieras de un país debe realizarse con estricto apego al orden, a la supervisión y fiscalización de las entidades competentes.

En cuanto a la organización del mercado secundario, la Ley Reguladora del Mercado de Valores dice: Artículo 22.- Organización.- "Los mercados secundarios de valores serán organizados por las bolsas de valores, previa autorización de la Superintendencia. En tales mercados, únicamente podrán negociarse y ser objeto de oferta pública las emisiones de valores inscritas en el Registro Nacional de Valores e Intermediarios."

Para Araya (1999) por oferta pública se entiende el acto por medio del cual una persona debe promover a los tenedores de acciones de una sociedad inscrita en el Registro Nacional de Valores e Intermediarios, su intención de adquirir, directa o indirectamente, en un solo acto o actos sucesivos, un volumen de acciones u otros valores de la misma. 


\section{Las bolsas de valores y los puestos de bolsa}

Corresponde a las Bolsas de Valores la organización del mercado secundario. En razón de ello la Ley las faculta para realizar las emisiones de valores que hayan sido debidamente inscritas en el registro que se lleve para ese efecto; igualmente podrán efectuar las negociaciones en dicho mercado tanto con títulos inscritos como no inscritos, pero las negociaciones que se hagan en ambas categorías tienen que estar debidamente separadas y no formarán parte de las carteras de los fondos de inversión que son objeto de supervisión por parte de la SUGEVAL.

Para García (2005) una fecha importante en la evolución de las bolsas, es la creación de la primera Sociedad Anónima, en 1600: La Compañía Inglesa de las Indias Orientales. A partir de este momento, las sociedades anónimas evolucionaron en paralelo con los mercados bursátiles.

Según Soto (2003), en Costa Rica, la Bolsa Nacional de Valores es una empresa privada cuyo objetivo es ser facilitador de las transacciones con valores o no, y ser un importante promotor del desarrollo del mercado de capitales.

Sobre la regulación y los requisitos para la inscripción de una bolsa de valores, la Ley reguladora del mercado de valores agrega:

Artículo 27.- Objeto.-Las bolsas de valores tienen por único objeto facilitar las transacciones con valores, así como ejercer las funciones de autorización, fiscalización y regulación, conferidas por la ley, sobre los puestos y agentes de bolsa. Se organizarán como sociedades anónimas y deberán ser propiedad de los puestos de bolsa que participen en ellas. Su capital social estará representado por acciones comunes y nominativas, suscritas y pagadas entre los puestos admitidos a la respectiva bolsa...

El Artículo 27 denota la función sustantiva de una Bolsa Valores, el cual es "facilitar" las transacciones, así como otras funciones de autorización y fiscalización propias ejercidas sobre los puestos de bolsa y los agentes. Entonces, la Bolsa de Valores ejerce una importante labor para el ejercicio de los principios que se han comentado de ética, transparencia y confianza que de privar en el ejercicio de las actividades del mercado de valores, y que permean hacia el público inversor.

Sobre las funciones más sustantivas de un Puesto de Bolsa, bajo los preceptos de la Ley reguladora del Mercado de Valores, dice:

Artículo 29.- Funciones y atribuciones.-Las funciones y atribuciones de las bolsas serán las siguientes: a) Autorizar el funcionamiento de los puestos de bolsa y de los agentes de bolsa, regular y supervisar sus operaciones en bolsa y velar porque cumplan con esta ley, los reglamentos de la Superintendencia y las normas dictadas por la bolsa de la que sean miembros, sin perjuicio de las atribuciones de la Superintendencia, c) Dictar los reglamentos sobre el funcionamiento de los mercados organizados por ellas, en los cuales deberá tutelarse la objetiva y transparente formación de los precios y la protección de los inversionistas.

A manera de ejemplo, la Figura 2 muestra la organización más relevante de la Bolsa Nacional de Valores de Costa Rica.

Otro elemento importante en la estructuración de los agentes que intervienenen la actividad de los mercados son los Puestos de Bolsa. 
FIGURA 2

\section{ORGANIZACIÓN BOLSA NACIONAL DE VALORES DE COSTA RICA}
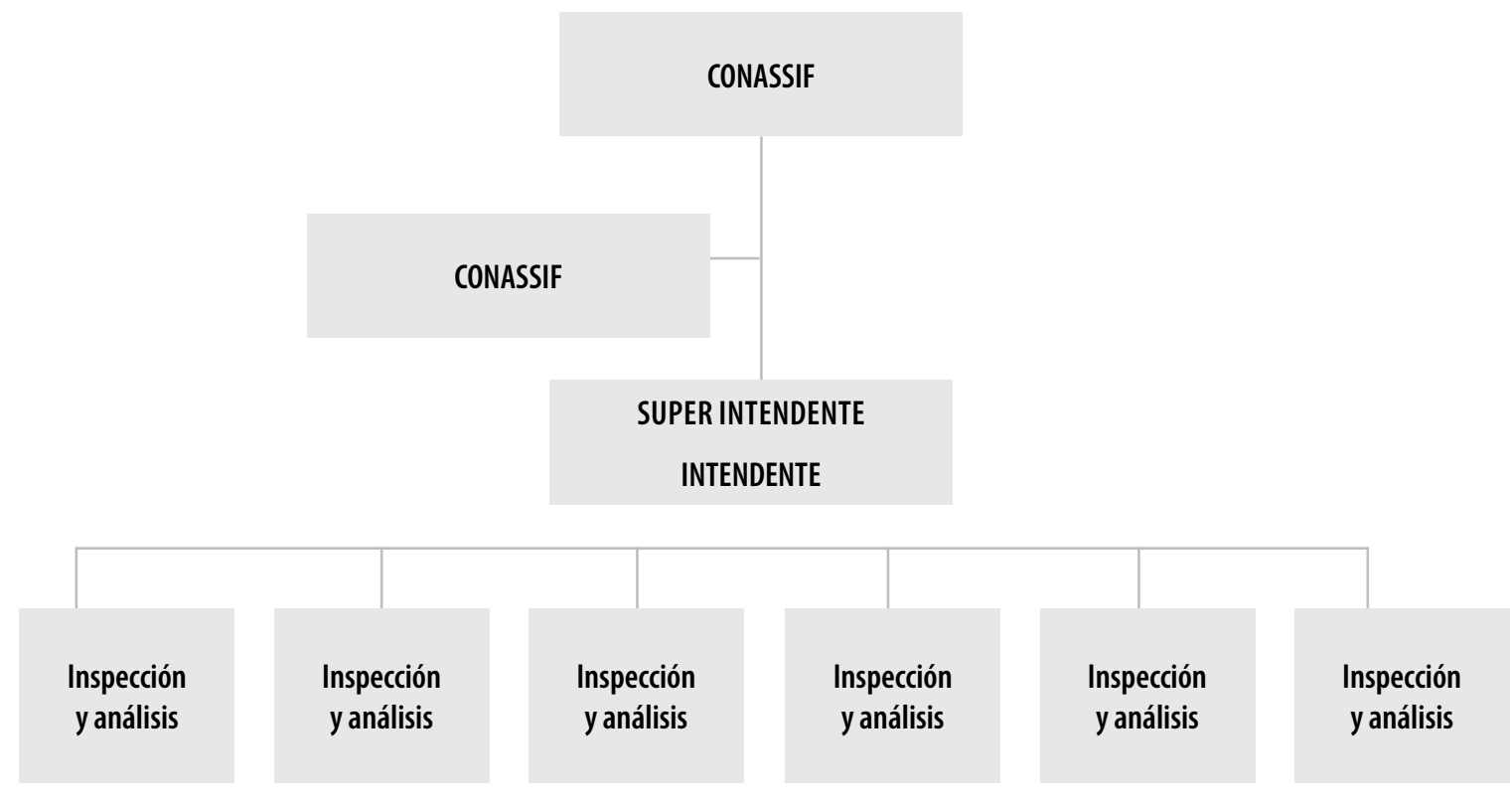

Fuente: www. Bolsacr.com

Según Meoño (2001), los puestos de bolsa son autorizados por las bolsas de valores correspondientes y de conformidad con los requisitos establecidos en la Ley 7732. Las operaciones que se efectúan en las bolsas de valores deben ser propuestas, perfeccionadas y ejecutadas por un puesto de bolsa. Solamente sociedades anónimas, creadas con el fin único de ser puesto de bolsa, podrán ser puestas en el mercado.

La naturaleza jurídica de un puesto de bolsa contempla lo siguiente: En cuanto a la naturaleza jurídica de los puestos de bolsa, la Ley de marras preceptúa:

Artículo 53.- Naturaleza de los puestos de bolsa. Los puestos de bolsa serán personas jurídicas, autorizadas por las bolsas de valores correspondientes y de conformidad con los requisitos establecidos en esta ley, para formar parte de ellas y, además, para realizar las actividades autorizadas en esta ley. Contra la decisión de autorizar un puesto de bolsa cabrá recurso de apelación ante la Superintendencia. Las operaciones que se efectúen en las bolsas de valores deberán ser propuestas, perfeccionadas y ejecutadas por un puesto de bolsa.

Como lo indica la norma de comentario, un puesto de bolsa debidamente autorizado se sujeta a todas las prescripciones legales que regulan su actuación, no solo en el plano económico, que es su giro usual, sino que también le alcanzan el cumplimiento de todos los postulados éticos que contiene la Ley Reguladora del Mercado de Valores, y ante una infracción comprobada por dicho agente, puede ser acreedor de una sanción legal. 


\section{Las Normas de Conducta en el manejo de la Información privilegiada o clasificada en materia de valores}

El principio de Protección al Inversor es de transcendental importancia para abordar el tema de las Normas de Conducta de los Agentes que participan del Mercado de Valores. Esto resulta así, ya que no se puede sostener tan importante y sensible actividad económica sin demostrar y practicar el principio de la confianza y de la debida protección al inversor, quien al final de cuentas resulta ser el elemento central sobre el cual gira el mercado de valores. Por lo tanto, debe darse, por parte de los agentes económicos y de la normativa, un cuerpo normativo robusto y firme que plasme dichas garantías hacia el Inversor.

Entonces sobre el Principio de Protección al inversor, se garantiza la estabilidad de las entidades financieras en protección de los inversionistas y en defensa del normal funcionamiento del mercado de valores. Particularmente el Derecho del mercado de valores responde a la necesidad de proteger los derechos de los inversionistas (Hernández, 2002).

Comparte Quesada (2003) este principio al mencionar que el sujeto principal de los mercados de valores es el inversionista, ya que este es el que aporta los recursos a ser trasladados entre los sujetos participantes del mercado. Es por esto que existe un principio esencial de proteccion al inversionista, ya que si el inversionista se encuentra protegido de los imprevistos abusivos que pudiera sufrir, va a seguir inyectando los recursos.

Teniendo clara la importancia del principio de protección al inversionista, como pilar estructural del mercado de valores, corresponde ahora identificar las normas que regulan el manejo y tratamiento de la información confidencial en la Ley Reguladora del Mercado de Valores (ver tabla 1).

\section{TABLA 1}

\section{ARTÍCULOS DE LA LEY REGULADORA DEL MERCADO DE VALORES QUE REGULAN EL TRATAMIENTO DE LA INFORMACIÓN CONFIDENCIAL}

\begin{tabular}{|c|l|}
\hline ARTÍCULO & \multicolumn{1}{|c|}{ NORMA DE CONDUCTA } \\
\hline 103 & Acceso a Información Privilegiada \\
\hline 104 & Prohibición de Adquirir Valores \\
\hline 105 & Información al Público \\
\hline 106 & Prioridad a clientes \\
\hline 107 & Abstenciones Obligatorias \\
\hline 113 & Responsabilidad Solidaria \\
\hline 114 & Conflicto de Intereses \\
\hline 166 & Infracción a la prohibición de divulgar \\
\hline
\end{tabular}

Fuente: Elaboración propia.

La Ley Reguladora del Mercado de Valores dispone en su Artículo 101: Normas y reglamentos internos.-Los participantes en el mercado de valores deberán respetar las normas de conducta establecidas en este capítulo. Las bolsas de valores deberán establecer reglamentos internos con normas de conducta, de acatamiento obligatorio para directores, personeros, asesores y empleados, así como para los puestos y agentes de bolsa.

La Ley Reguladora del Mercado de Valores ordena que los postulados de conducta para los agentes participantes del Mercado de Valores son de acatamiento obligatorio, y por lo tanto corresponde a cada uno de ellos incorporar dentro de su normativa interna todo lo referente al campo de las normas de conducta. 
Sobre la información privilegiada se indica:

Artículo 102.- Manejo de información privilegiada.-Quienes dispongan de alguna información privilegiada deberán abstenerse de realizar, directa o indirectamente, cualquier tipo de operación en el mercado sobre los valores a que se refiere dicha información. Igualmente, deberán abstenerse de comunicarla a terceros o de recomendar operaciones con dichos valores. Para los efectos de esta ley, se entiende por información privilegiada toda información concreta, referente a uno o varios valores o a sus emisores, que no haya sido dada a conocer al público y pueda influir en los precios de dichos valores.

El primer elemento que se desprende, es referido a que la persona que tenga acceso a información privilegiada no debe ejecutar operaciones en materia de valores a las que se encuentre referida esta. Así mismo, se debe abstener de comunicarla a terceras personas.

Es importante acotar, que para el caso del régimen de responsabilidad, en general las actuaciones se sancionan con dolo o culpa grave para el caso de los funcionarios públicos según lo dispone la Ley General de la Administración Pública. Esto aplica cuando el funcionario mantiene un contrato de trabajo con la Administración Pública. Para el funcionario que labora para una sociedad o bien para un patrono privado dichas abstenciones o normas de conducta ética también le afectan, por lo tanto, en los contratos de trabajo de estos colaboradores tiene que existir un apartado sobre el manejo de la información privilegiada y sus consecuencias legales ante la falta demostrada de cumplimiento.

Igualmente sí se tipifica la conducta bajo alguno de los Delitos Especiales que contiene la
Ley Reguladora del Mercado de Valores en los Puestos de Bolsa, independientemente de que sean Sociedades Anónimas, sus representantes legales o bien sus agentes deben demostrarles un comportamiento doloso o culposo según los preceptos del Código Penal de Costa Rica.

Así mismo, el concepto de información privilegiada queda claramente delimitado, por lo que se entenderá como aquella información concreta referida a valores o a emisores que no haya sido puesta al conocimiento de público, y que pueda influir en los precios de los valores.

Es relevante esta definición, ya que al tratarse de materia de valores, se refiere entonces a rendimientos económicos, ganancias en puestos de bolsas, mega fondos de inversión o los inmobiliarios, en los que la Ley exige dentro de su postulado normativo, que la información no haya sido conocida por el público, y que pueda afectar o bien distorsionar su precio.

Esta situación es comprensible en el entorno de los mercados de valores, siendo susceptibles a las afectaciones o distorsiones tanto del mercado interno como el internacional, y el que se genere información de "primera mano" puede causar un lucro desmedido para ciertas personas que sabrán de antemano el comportamiento del mercado de valores, o bien, pueden provocar una especulación sobre una determinada inversión, lo cual podría generar eventualmente un caos financiero dentro de las regulaciones económicas de un país.

En cuanto a las personas a las que se faculta el acceso a la información clasificada, se establece en el Artículo 103 los funcionarios específicos que en razón de su puesto, jerarquía o funciones puedan tener acceso a la misma. Es importante mencionar que la Ley Reguladora establece una tipología de estas personas, ya que en caso de infracción a los postulados de 
comportamiento o de conductas se les exigirá, a través de los mecanismos del debido proceso que rindan las explicaciones necesarias sobre la conducta que presuntamente se les imputa.

De igual forma, para los sujetos anteriormente indicados, la Ley Reguladora del Mercado de Valores, les impone una prohibición específica:

Artículo 104.- Prohibición de adquirir valores.- Las personas a que se refiere el párrafo anterior deberán abstenerse de realizar, directamente o mediante interpósita persona, la adquisición de valores de cualquier clase emitidos por la sociedad con la que se encuentren relacionados en virtud de su cargo o su vínculo, durante un plazo de tres meses, contado a partir de la última enajenación que hayan realizado respecto de cualquier clase de valores emitidos por la misma sociedad. Igual abstención deberá observarse para la enajenación y la posterior adquisición realizada de cualquier clase, emitidos por la sociedad de que se trate.

También la Ley Reguladora del Mercado de Valores contiene una serie de disposiciones relativas al comportamiento ético de los agentes físicos o jurídicos que intervienen en el mercado de valores, y que en el ejercicio de su cargo puede llegar a manejar información privilegiada o sensible, según su Artículo 107, denominado "Abstenciones obligatorias", y dentro de las cuales se enuncias las siguientes : Los participantes del mercado que asesoren a sus clientes deben de abstener de provocar un daño o beneficio a sus clientes en la evolución de precios, provocar una multiplicación de transacciones que pueden ser innecesarias que puedan no significar un beneficio para el cliente, de igual forma que pueda anteponer los valores propios o de empresa o de su grupo de interés a la venta de los valores de sus clientes, también se deben de abstener de otorgar beneficios a su cliente en beneficio de los demás, no debe tampoco utilizar valores para negociación que le han sido conferidos para su confianza, conexamente el difundir información falsa o inexacta sobre cualquier situación que pueda conllevar a una situación negativa en el mercado de valores.

En cuanto a los alcances de las personas físicas o jurídicas que quebranten las disposiciones anteriormente dichas, la Ley Reguladora dispone:

Artículo 113.- Responsabilidad solidaria.-Los puestos, los agentes de bolsa, las sociedades administradoras de fondos de inversión y demás personas autorizadas para colocar participaciones de fondos de inversión, serán responsables solidarios de los daños y perjuicios que sufra cualquier inversionista, cuando no haya sido advertido de los riesgos de las inversiones propuestas.

De igual forma, la Ley Reguladora señala las consecuencias por la violación a estos deberes, situación que puede generar una responsabilidad solidaria hacia los presuntos sujetos que hayan cometido la infracción. Obviamente la sanción en primera instancia se regula únicamente en el resarcimiento económico en beneficio de los actos no haciendo remisión expresa hacia otra normativa en el ámbito penal.

La Ley Reguladora aborda el tema del conflicto de intereses, y cómo media la intervención de la SUGEVAL ante dichas situaciones y que se contempla en el Artículo 114 denominado "Norma Reguladora de Conflictos de Intereses", atendiendo la primera de ellas al incurrir en la prohibición de determinadas operaciones pertenecientes a un mismo grupo o financiero o grupo de interés económico, también debe incluirse un régimen de incompatibilidades aplicable a los sjetos fiscalizados y que prevenga el traspaso de información en perjuicio del públi- 
co inversionista y finalmente que se incluya en los reglamentos cualquier otra situación que tienda a prevenir los conflictos de intereses.

\section{Las sanciones por infraccion a las normas de conducta}

Las sanciones por las infracciones graves que contempla la Ley Reguladora del Mercado de Valores, se menciona: Artículo 160.- Sanciones por infracciones graves.- Las sanciones correspondientes a las infracciones graves, serán: 1.Amonestación pública que se publicará en "La Gaceta" y en un diario de circulación nacional, 2.- Multa por un monto de tres veces el beneficio patrimonial, obtenido como consecuencia directa de la infracción cometida, 3.- Multa del dos por ciento (2\%) del patrimonio de la sociedad, 4.- Multa de cien veces el salario base definido en la Ley $N^{\circ}$ 7337, de 5 de mayo de 1993, 5.- Suspensión o limitación del tipo o volumen de las operaciones o actividades que pueda realizar un infractor en el mercado de valores, por un año, 6.- Suspensión de la condición de miembro del mercado organizado correspondiente, por un año"

Para la imposición de estas sanciones debe cumplirse con las garantías constitucionales del debido proceso que se consagran en el Artículo 39 de la Constitución Política de Costa Rica, donde se debe comprobar la culpabilidad de la persona investigada mediante el debido ejercicio de su derecho a la defensa, comprendiendo este una notificación de un traslado de cargos debidamente estructurado y fundamentado que respete los principios de imputación e intimación. De igual forma, debe darse el espacio para que se realice una audiencia, donde la persona investigada aportará toda la prueba que estime necesaria para su defensa, y finalmente la resolución final de proceso.
En cuanto al funcionario infractor a los deberes en el manejo de la información clasificada o confidencial, se menciona:

Artículo 166.- Prohibición de divulgar información.-Salvo los casos previstos en esta ley y sus reglamentos, en cuanto a la difusión de información relevante para el público inversionista o, salvo orden judicial, quedará prohibido a los directivos, funcionarios, empleados y asesores de la Superintendencia, divulgar información relativa a los sujetos fiscalizados y a las transacciones de los mercados de valores, que conozcan en virtud de su cargo. Tal prohibición se mantendrá aun cuando las citadas personas dejen de prestar sus servicios a la Superintendencia, hasta tanto la respectiva información no se haga pública.

\section{Reglamento sobre Políticas de Prevención de Uso de Información Privilegiada}

Este Reglamento emanado en el año 2009 por el Consejo Nacional de Supervisión del Sistema Financiero, contiene una definición precisa de información privilegiada:

Artículo 20- Definición de información privilegiada. Se entiende por información privilegiada toda información concreta, referente a uno o varios valores o a sus emisores, que no haya sido dada a conocer al público y pueda influir en los precios de dichos valores. Por información concreta se entiende aquella que hace referencia a hechos o circunstancias que se han presentado, se están presentando, o puede esperarse razonablemente que se produzcan, cuando de esa información puedan extraerse conclusiones sobre posibles efectos en los precios de los valores. 
El reglamento de comentario establece con mayor precisión el concepto de información privilegiada, entiéndase entonces como la información concreta a uno o varios emisores y que puede influir en los precios de los valores. La formación del precio de los valores puede darse bajo las correctas prácticas y se establece por parte de la SUGEVAL y de los agentes o participantes del mercado de valores. Por lo tanto, este reglamento viene a reforzar en mayor grado el principio de protección al inversor. La confianza en un sistema financiero es el pilar estratégico sobre el cual descansa su verdadera sostenibilidad, esto aunado a criterios de transparencia, buena fe negocial, igualdad de trato, entre otros que surgen del cotidiano devenir del mercado.

De igual manera, se establece normativamente, todo lo relativo a la comunicación a la SUGE$V A L$, en el manejo de la información privilegiada. El Articulo 5 ordena que se debe remitir a la Superintendencia el hecho relevante de carácter confidencial, donde se indique los valores sobre los cuales se dispone de la información privilegiada de las personas y las fechas que puedan haber tenido acceso a esta. El reglamento brinda un plazo de 5 días hábiles para la remisión de esta información a partir del momento en que se tuvo conocimiento de este hecho. Igualmente se solicita que se acompañe una declaración jurada donde las personas que han tenido acceso a este tipo de información sepan de los alcances e implicaciones de esta situación.

Se establece un protocolo de actuación para el manejo de información privilegiada, en el Artículo 6 del Reglamento, lo anterior en caso de que existan sospechas de que haya información privilegiada que se esté utilizando o pueda ser utilizada con fines ilícitos. Este protocolo tiene que incluir a los responsables directos para adoptar las medidas, sanciones disciplinarias en casos de incumplimiento, salvo las que correspondan a SUGEVAL. De igual manera, en caso de que el protocolo sea activado ante la sospecha de uso de la información privilegiada, debe comunicarse por parte inmediatamente a la SUGEVAL y notificar a más tardar al dia siguiente sobre las medidas adoptadas.

\section{Conclusiones}

La estructuración del mercando financiero en Costa Rica ha obedecido a una clara visión por parte del legislador de procurar un ejercicio adecuado de las actividades económicas y financieras en un marco regulado, supervisado y fiscalizado por distintas entidades que llevan a cabo dichas labores.

La Superintendencia General de Valores es una entidad especializada, mediante la cual le fue delgada por Ley ordinaria de la República velar por la correcta organización del mercado primario y secundario de los Valores en Costa Rica

La Legislación Nacional brinda una amplia gama de facultades para el ejercicio de las labores ordinarias de la SUGEVAL, las cuales son de cumplimiento obligatorio para todos los agentes económicos que participan de la actividad finaciera de Costa Rica.

El manejo de la información privilegiada en materia del mercado valores se cimienta sobre un bien jurídico fundamental como es la "confianza" del público inversionista en el sistema, esto para proteger la adecuada formación de precios en los mercados financieros.

Lo anterior es importante, ya que en parte la estabilidad de un país se mide entre otros aspectos con la seguridad financiera tanto a nivel interno como para los inversionistas extranjeros. En razón de ello, el país tiene que cumplir con 
ciertos criterios de confiabilidad, seguridad, y transparencia en el manejo de la información, ya que la falta a esos deberes podría generar un caos financiero y consecuentemente debilitar su credibilidad.

La Ley Reguladora del Mercado de Valores de Costa Rica establece claras sanciones por la comisión de infracciones que incurran los agentes que intervienen en el manejo de la información privilegiada, y que con ello se beneficien o beneficien a otros con su divulgación. El tipo de sanciones es variado, van desde las de tipo económico, la cesación del funcionario infractor, hasta llegar a las denuncias de tipo penal o de índole civil según sea el caso, siempre en respeto de las garantías del debido proceso constitucional como eje rector de nuestro sistema sancionatorio.

La Sala Cuarta Constitucional de Costa Rica, que declaró sin lugar una acción de inconstitucionalidad contra las infracciones y sanciones contenidas en la Ley Reguladora del Mercado de Valores, viene a fortalecer el sistema de fiscalización de la Superintendencia General de Valores, ya que esas infracciones pueden ser conocidas y sancionadas por la Superintendencia en sede administrativa, siempre que se respeten todas las garantías sustantivas del debido proceso que se derivan del Artículo 39 de la Constitución Política, y que han sido ampliamente desarrolladas por la jurisprudencia vinculante de la Sala Cuarta Constitucional.

\section{Referencias}

Araya, D. y Wilson, S. (1999). Principales críticas a la nueva Ley reguladora del mercado de valores desde una perspectiva civil y mercantil. (Tesis Inédita de Licenciatura). Universidad de Costa Rica, San José, Costa Rica.

Arias, P. (1998). Delito financiero y delito bursatil: analisis de los principios politico criminales para orientar una reforma al codigo penal. (Tesis Inédita de Licenciatura). Universidad de Costa Rica, San José, Costa Rica.
Asamblea Legislativa. (1949). Constitución Política. San José, Costa Rica: Editorial Costa Rica.

Asamblea Legislativa. (1995). Ley Orgánica del Banco Central de Costa Rica. San José Costa Rica: Editorial Costa Rica.

Asamblea Legislativa. (2008). Ley Reguladora del Mercado de Valores. San José, Costa Rica: Editorial Costa Rica.

Camacho, A. (2001). Impulso de los Mercados Financieros en Centroamérica. Alajuela, Costa Rica: CLACDS, INCAE.

Consejo Nacional de Supervisión del Sistema Financiero. (2009). Reglamento sobre Políticas de Prevención de Uso de Información Privilegiada. Publicado en el Diario Oficial La Gaceta n. 212 del 2 de noviembre del 2009.

García, F. (2005). Bolsa, Mercados y Técnicas de Inversión. Mc Graw Hill: Madrid, España.

Hernández, A. (2002). Derecho Bursátil (Mercado de Valores) Tomo I. San José, Costa Rica: Investigaciones Jurídicas.

Matarrita, R y Ledezma, J. (s.f) Aspectos Generales del Mercado de Valores Costarricense. Bolsa Nacional de Valores. Recuperado de www.rodrigomatarrita.com/inc/ download.php?file=../archivos/

Meoño, B. (2001). Operaciones Bursátiles. San José Costa Rica: EUNED.

Méndez, R. (s.f) La Bolsa y los Títulos Valores en Costa Rica. Recuperado de www.hacienda.go.cr/

Morales, F. (2003). La ejecución de los contratos de bolsa a la luz de la nueva Ley reguladora del mercado de valores: validez de las ejecuciones forzosas realizadas por la Bolsa Nacional de Valores. (Tesis Inédita de Licenciatura). Universidad de Costa Rica, San José, Costa Rica.

Lamothe P. y Pérez, M. (2003). Opciones Financieras y Productos Estructurados. Mc Graw Hill: Madrid, España.

Ortiz, L. (2005). La Responsabilidad in vigilando del Banco Central de Costa Rica por la Supervisión del Sistema Financiero Nacional. San José, Costa Rica: Instituto Iberoamericano de Derecho Administrativo.

Poder Judicial, Sala Cuarta de la Corte Suprema de Justicia, Voto 6976-2011

Procuraduría General de la República en Dictamen C-1222007 del 18 de abril 2007.

Procuraduría General de la República ha mencionado en Dictamen C-222-2001 del 8 de Agosto del 2001. 
RNA Revista Nacional de Administración

Procuraduría General de la República en Dictamen C-3202005, 6 de setiembre 2005.

Procuraduría General de la República, Dictamen C-3342006 de 23 de agosto de 2006.

Quesada, A. (2003). Infracciones a la Ley reguladora del mercado de valores y delitos bursátiles. (Tesis Inédita de Licenciatura). Universidad de Costa Rica, San José, Costa Rica.

Rodríguez, R. (1995). Análisis de los puestos de bolsa a la luz de la Ley reguladora del mercado de valores. (Tesis Inédita de Licenciatura). Universidad de Costa Rica, San José, Costa Rica.

Rojas, A. (1997). Sobre la Intermediación Financiera. Revista Ivstitia, 129.

Recibido: 6 de julio de 2013

Aceptado: 28 de octubre de 2013 